\title{
Electrochemical characterization of pulsed layer deposited hydroxyapatite-zirconia layers on Ti-21Nb-15Ta-6Zr alloy for biomedical application
}

\author{
Javier Izquierdo ${ }^{1}$, Georgiana Bolat ${ }^{2}$, Nicanor Cimpoesu ${ }^{3}$, Lucia Carmen Trinca ${ }^{4}$, \\ Daniel Mareci², Ricardo Manuel Souto ${ }^{1,5}$ \\ ${ }^{1}$ Department of Chemistry, Universidad de La Laguna, E-38200 La Laguna (Tenerife), Spain \\ 2 “Gheorghe Asachi” Technical University of Iasi, Faculty of Chemical Engineering and Environmental \\ Protection, 73 Prof. Dr. Doc. D. Mangeron Street, 700050 Iasi, Romania \\ 3 “Gheorghe Asachi” Technical University of Iasi, Faculty of Materials Science, 61-63 Prof. Dr. Doc. \\ D. Mangeron Street, 700050 Iasi, Romania \\ ${ }^{4}$ Science Department, University of Agricultural Sciences and Veterinary Medicine, M. Sadoveanu Alley \\ 3, 700490 Iasi, Romania \\ ${ }^{5}$ Institute of Material Science and Nanotechnology, Universidad de La Laguna, E-38200 La Laguna \\ (Tenerife), Spain
}

\begin{abstract}
A new titanium base Ti-21Nb-15Ta-6Zr alloy covered with hydroxyapatite-zirconia (HA-ZrO $\left.{ }_{2}\right)$ by pulsed laser deposition (PLD) technique was characterized regarding its corrosion resistance in simulated physiological Ringer’s solution at $37^{\circ} \mathrm{C}$. For the sake of comparison, Ti-6Al-4V standard implant alloy, with and without hydroxyapatite-zirconia coating, was also characterized. Multiscale electrochemical analysis using both conventional averaging electrochemical techniques, namely electrochemical impedance spectroscopy (EIS) and potentiodynamic polarization, and spatially-resolved microelectrochemical techniques (scanning electrochemical microscopy, SECM) were used to investigate the electrochemical behaviour of the materials. In addition, scanning electron microscopy evidenced that no relevant surface morphology changes occurred on the materials upon immersion in the simulated physiological solution, despite variations in their electrochemical behaviour. Although uncoated metals appear to show better performances during conventional corrosion tests, the response is still quite similar for the $\mathrm{HA}-\mathrm{ZrO}_{2}$ coated materials while providing superior resistance towards electron transfer due to the formation of a more dense film on the surface, thus effectively behaving as a passive material. It is believed corrosion of the $\mathrm{HA}-\mathrm{ZrO}_{2}$ coated $\mathrm{Ti}-21 \mathrm{Nb}-15 \mathrm{Ta}-6 \mathrm{Zr}$ alloy will have negligible effect upon biochemical and cellular events at the bone-implant interface and could facilitate osseointegration.
\end{abstract}


Keywords: Ti alloys; Pulsed layer deposition; hydroxyapatite-zirconia coating; electrochemical impedance spectroscopy; scanning electrochemical microscopy; biomaterial.

\section{Introduction}

Titanium-based alloys have been considered as substitutes of damaged bones and joints since long ago. The suitability of titanium-based materials stems from their high resistance to corrosion, as well as their good biocompatibility in terms of mechanical properties and biochemical interaction with living tissues [1]. Its low elastic modulus and high strength, combined with the ease for bone tissues to grow on the highly stable $\mathrm{TiO}_{2}$ layer (i.e. osseointegration), confer titanium-based materials attractive properties for their application as biomedical implants [1-3], which motivated the early introduction of commercially pure titanium (cp Ti) and the even more widely employed Ti-6Al-4V alloy in biomedicine. However, Ti-6Al-4V exhibits still rather high elastic modulus (110 GPa) when compared to cortical bone (10-30 GPa) [4], and eventual metal ion release may result from the metastable current transients, undergone by the alloy in physiological solution [5]. Moreover, concerns related to the hazardous accumulation of vanadium and aluminium has risen due to the adverse effects of such elements [6-8]. For this reason, efforts are currently made by scientists in order to develop new titaniumbased alloys containing non-toxic alloying elements for the stabilization of the body cubic centered $\beta$ phase, hence enhancing the biocompatibility [3,4,9]. Transition metals such as Mo, Ta, Zr, Nb or Sn are regarded to satisfy this objective without exhibiting cytotoxic or allergenic responses $[4,10,11]$. Among them, $\mathrm{Zr}$ shows superior corrosion resistance and biocompatibility when alloyed with Ti due to the action of the $\mathrm{ZrO}_{2}$ layer developed on the surface [12,13], and something similar occurs with Ta due to the corresponding $\mathrm{Ta}_{2} \mathrm{O}_{5}$ layer [14]. Another $\beta$-stabilizing element fulfilling these requirements is $\mathrm{Nb}$, and it has been employed in some ternary and quaternary alloys $[15,16]$.

The biocompatibility of biomaterials may be further tuned by the surface modification of the material, still avoiding inflammatory or immunologic response. Diverse techniques have been applied to prepare bioactive films on potentially applicable biomaterials, although with traditional techniques such as plasma spraying is difficult to control critical parameters for the bioresorbability, namely the crystallinity, phase composition and morphology of the prepared films [17-19]. As an alternative, pulsed laser deposition (PLD) is an extremely versatile technique for the preparation of a wide range of thin films and multilayered structures for any kind of materials [20-24]. The principle of PLD is a very complex physical phenomenon. It does not only involve the physical process of the laser-material 
interaction of the impact of high-power pulsed radiation on the solid target, but also the formation of a plasma plume with high energetic species, and even the transfer of the ablated material through the plume onto the heated substrate surface. If a solid or liquid is irradiated with an intense laser beam, a small amount of material on the surface is vaporized and ejected away from de sample. This vapour is a collection of atoms, molecules, ions and electrons, the exact ratio and kinetic energy of which is dependent on the laser parameters, and at some degree on the target sample as well. Repeated pulses of laser light and subsequently repeated vapour plumes might build up material on the surface to form what is termed a thin film [20-22,25].

Hydroxyapatite (HA) is currently used as biomaterial for many applications in dentistry and orthopaedics, because it forms a real bond with the surrounding bone tissue when implanted. HA films are often applied on metallic substrates such as titanium and its alloys. These implants not only bond strongly with bone tissue on their surface without eliciting foreign body response in cultured cell tests [26,27], but also have excellent mechanical performances [28,29]. Unfortunately, the interfacial strength between the substrate and the HA film is normally very low, leading to the failure of the implant [30]. For further improvement of the bioactivity and adhesive strength of the HA films, the addition of composites films have been introduced [31]. Zirconia $\left(\mathrm{ZrO}_{2}\right)$ has also been commonly used as reinforcement for many ceramics because of the chemical inertness and excellent mechanical properties. Therefore, it is desirable to combine the advantages of $\mathrm{ZrO}_{2}$ as reinforcement for $\mathrm{HA}$ [32].

For the evaluation of the electrochemical behaviour and corrosion resistance of new developed biomaterials, the electrochemical techniques usually employed are dynamic polarization and electrochemical impedance spectroscopy (EIS), because they provide valuable information about the general behaviour of the passivating oxide layers formed on the metals [13,16,33]. More recently, complementary information concerning the ability towards the electron transfer has been gathered using localized microelectrochemical techniques such as the scanning electrochemical microscopy (SECM) operated in the feedback mode $[13,34,35]$. This technique makes use of an ultramicroelectrode (UME), which is rastered in the close vicinity of the substrate surface while a redox mediator species is forced to react at the UME under diffusion-limited conditions. In this way, the current flowing through the UME is the spatially- resolved signal. The eventual ability of the passivated surface to regenerate the mediator, hence leading to a local increase in the mediator concentration and a consequent UME current increase, reflects the enhanced electron-transfer kinetics of the metal substrate [13,34-36]. This allows the 
evaluation of the (in)homogeneous surface conductivity and the ease to conduct electrochemical reactions at the surface, inherently related to its corrosion susceptibility.

In this work we report on the electrochemical behaviour of a new quaternary alloy, Ti-21Nb-15Ta-6Zr, in comparison with the widely used Ti-6Al-4V biomaterial, upon surface modification with hydroxyapatite-circonia $\left(\mathrm{HA}^{-} \mathrm{ZrO}_{2}\right)$ coatings deposited by PLD. The deposition process resulted in compact and homogeneous coating deposits, as evidenced by scanning electron microscopy (SEM) images. Scratch tests combined with electrochemical characterization were employed to evaluate the potential bone integration of the new material. The average surface properties and their evolution during the first 7 days of exposure to simulated physiological environment have been analyzed using EIS, while the corrosion rate at the longest exposure time has been estimated by dynamic polarization. In addition, the local surface conductivity has been monitored by SECM operated in the feedback mode, by analysing both probe approach curves and 2-D surface scans. Although uncoated metals appear to show better performances during conventional corrosion tests, the response is still quite similar for the $\mathrm{HA}-\mathrm{ZrO}_{2}$ coated materials, which in addition provide superior resistance towards electron transfer due to the formation of a more dense film on the surface.

\section{Experimental section}

\subsection{Materials}

Two Ti alloys with different composition (given in wt.\%) were used as the substrate material: Ti6Al-4V and Ti-21Nb-15Ta-6Zr alloys. The layers on both Ti alloys produced by the pulsed layer deposition (PLD) process were obtained from hydroxyapatite-zirconia $\left(\mathrm{HA}^{-} \mathrm{ZrO}_{2}\right)$ synthesized by ultrasound irradiation [32]. A scanning electron microscope (SEM) Tescan VEGA II LMH, equipped with an EDX detector, was employed to visualize the topographical features and obtain elemental analysis of the coated materials as deposited, or following either mechanical or electrochemical testing. $\mathrm{X}$-ray diffraction (XRD) was employed for the identification the phase structure. XRD spectra were recorded using an X'Pert PRO MRD (PANalytical, Almelo, The Netherlands) diffractometer equipped with a $\mathrm{Cu} \mathrm{K}_{\alpha}$ anode.

The PLD process was performed with a $10 \mathrm{~ns}$ Nd:YAG pulsed laser beam (Continuum Surelite). The second harmonic $(\lambda=266 \mathrm{~nm})$ of the laser was focused by an $f=25 \mathrm{~cm}$ lens onto an $\mathrm{HA}-\mathrm{ZrO}_{2}$

round shape compacted target, placed in a vacuum chamber (evacuated to $10^{-3}$ Torr residual pressure). 
The growth of the thin layer was done in a vacuum chamber at $10^{-3}$ Torr pressure and the substrate was placed at a target-substrate distance of $30 \mathrm{~mm}$. The laser radiation $(40 \mathrm{~mJ})$ was focused on a $1.5 \mathrm{~mm}^{2}$ area on the target. The ablation time was 1800 seconds and the target was continuously moved using an $X Y$ translation system so all the time a new material was ablated.

Wettability of the surface preparations of the $\mathrm{HA}-\mathrm{ZrO}_{2}$ coated $\mathrm{Ti}$ alloys was established by contact angle measurements, that. were performed using an EasyDrop instrument (Krüss GmbH, Hamburg, Germany) controlled by a personal computer equipped with Drop Shape Analysis specific software. A tribometer UMTR 2M-CTR (Bruker, Billerica, MA, USA) with disc pinion system was employed to characterize the friction behaviour of the $\mathrm{HA}-\mathrm{ZrO}_{2}$ coated Ti alloys.

Prior to electrochemical testing, the uncoated Ti alloys were mirror-polished with 400 to 4000 grit emery papers and subsequently polished using alumina suspension, washed with twice distilled water, ultrasonically degreased in ethanol, and dried in air.

\subsection{Electrochemical testing}

Electrochemical measurements were performed in Ringer's physiological solution. This was prepared by dissolving $6.5 \mathrm{~g} \mathrm{~L}^{-1} \mathrm{NaCl}, 0.42 \mathrm{~g} \mathrm{~L}^{-1} \mathrm{KCl}, 0.25 \mathrm{~g} \mathrm{~L}^{-1} \mathrm{CaCl}_{2}$ and $0.2 \mathrm{~g} \mathrm{~L}^{-1}$ of $\mathrm{NaHCO}_{3}$ in miliQ water $\left(18.2 \mathrm{M} \Omega \mathrm{cm}^{-1}\right)$. All chemicals were of analytical grade purchased from Merck (Darmstadt, Germany). The $\mathrm{pH}$ of the solution was found to be 6.8 at room temperature. Ferrocenemethanol (Sigma Aldrich) was added in $0.5 \mathrm{mM}$ concentration to the Ringer's solution when experiments were done using the SECM technique.

For the dynamic polarization and the impedance measurements, the Ti alloy samples, either coated with $\mathrm{HA}-\mathrm{ZrO}_{2}$ or uncoated, were placed in a glass corrosion flow cell kit (C145/170, Radiometer, France), which was filled with the Ringer's solution. A saturated calomel electrode was used as the reference electrode, and a platinum coil as the counter electrode. The potentials in this paper are reported versus the saturated calomel electrode (SCE). The temperature of the electrochemical cell was maintained at $37 \pm 1{ }^{\circ} \mathrm{C}$ with the aid of a thermostat. Electrochemical measurements were performed using a potentiostat model PARSTAT 4000 (Princeton Applied Research, NJ, USA). The instrument was controlled by a personal computer and VersaStudio software.

Electrochemical impedance spectra were measured over a frequency range extending from 100 $\mathrm{kHz}$ to $1 \mathrm{mHz}$ using a $10 \mathrm{mV}$ amplitude AC voltage signal. The EIS tests were recorded at the open 
circuit potential (OCP) developed by the samples after 1-hour, 1-day, and 1-week of immersion in the Ringer's solution maintained at $37^{\circ} \mathrm{C}$. Analysis of the spectra was performed in terms of equivalent circuit (EC) fitting using ZSimpWin software. The linear potentiodynamic polarization tests were initiated after 1-week immersion of the samples in the Ringer's solution, by scanning the potential at the rate of $1 \mathrm{mV} \mathrm{s}^{-1}$ from $-1.0 \mathrm{~V}_{\text {SCE }}$ up to $+1.0 \mathrm{VSCE}$.

A scanning electrochemical microscope acquired from Sensolytics (Bochum, Germany) was used for the SECM experiments, controlled with personal computer. Platinum UME's, with $12.5 \mu \mathrm{m}$ diameter platinum microdisk sealed in glass, were produced by standard procedures [37]. Glass capillaries with outer and inner diameter 1.5 and $1.15 \mathrm{~mm}$, respectively, were employed for the UME fabrication along with platinum wire of $12.5 \mu \mathrm{m}$ diameter (Goodfellow, Cambridge, UK). A thermostatable sample holder developed by Metrohm-Autolab (Utrecht, The Netherlands) served to maintain the metal samples at approximately $37^{\circ} \mathrm{C}$ during the experiments. This holder consisted of a metallic base with an internal circuit for the circulation of warm water, plus a metacrylate lid to be fitted on top of the metallic base. The investigated sample was placed in between these two components facing up, with an o-ring preventing leakage. The Ti alloys were left unbiased at their spontaneous OCP in Ringer's solution during measurements. An $\mathrm{Ag} / \mathrm{AgCl} / \mathrm{KCl}(3 \mathrm{M})$ and a platinum wire were used as reference and counter electrodes, respectively. The potentials were subsequently expressed with relation to the saturated calomel electrode (SCE) for consistency.

SECM experiments were done with the tip biased at $+0.47 \mathrm{~V}_{\mathrm{SCE}}$, ensuring oxidation of ferrocenemethanol as redox mediator under diffusion-controlled conditions. The tip was initially approached to the substrate with the aid of a video-camera, and then a probe approach curve (PAC) was recorded at $2 \mu \mathrm{m} \mathrm{s}^{-1}$ (1 $\mu \mathrm{m}$ step) until clear alteration of the tip current response was obtained as a result of the surface proximity (to be discussed in the next section). PAC's were recored in three different positions of the investigated surface in order to ensure that any tilt of the surface was taken into account. Then, a randomly-selected $250 \mu \mathrm{m} \times 250 \mu \mathrm{m}$ surface was scanned at a constant distance of $10 \mu \mathrm{m}$ using $30 \mu \mathrm{m} \mathrm{s}^{-1}$ scan rate. All the tip current data reported in this work have been normalized by dividing the current values measured at each location by the tip current measured in the bulk of the solution under the same conditions. Normalized distances refer to the tip-sample distance values divided by the diameter of the UME (i.e., $12.5 \mu \mathrm{m})$. 


\section{Results and discussion}

\subsection{Structural characterizations of the coatings}

The typical surface morphologies and compositions of the $\mathrm{HA}-\mathrm{ZrO}_{2}$ compacted target, and the coatings deposited by PLD on the titanium-based alloys were characterized by scanning electron microscopy (SEM) provided with energy dispersive X-ray spectroscopy (EDX) analysis. Micrographs and elemental distributions for each material are given in Figure 1. EDX analysis confirmed the presence of $\mathrm{Ca}, \mathrm{P}$, and $\mathrm{Zr}$ in the compacted target, and the absence of other elements apart oxygen are considered to establish the purity of the material. The same observations are valid for the $\mathrm{HA}-\mathrm{ZrO}{ }_{2}$ coated Ti alloys as shown in Figure 1B-C. Furthermore, the variation in surface topography experienced by coating the $\mathrm{Ti}$ alloys with a thin layer of $\mathrm{HA}-\mathrm{ZrO}_{2}$ is shown using $\mathrm{SEM}$ in Figure 2. The metallic surfaces covered by the $\mathrm{HA}-\mathrm{ZrO}_{2}$ layer exhibited a high density of pores and splats, in contrast to regions of the alloy surface that were left uncoated for comparison purposes. In addition, the X-ray diffractometry pattern depicted in Figure 3 confirms that all diffraction peaks directly correlate to the hydroxyapatite and zirconia constituents in the coating deposited on the Ti-21Nb-15Ta-6Zr alloy.

The formation of a more hydrophilic surface by coating the surface of the alloys with the $\mathrm{HA}-\mathrm{ZrO}_{2}$ layer was deduced from contact angle measurements as shown in Figure 4. Both Ti-21Nb15Ta-6Zr alloy and Ti-6Al-4V alloy (not shown) exhibited a major decrease in the water contact angles $(\theta)$ compared to the uncoated materials. Thus, the measured contact angle was $79^{\circ}$ for uncoated Ti21Nb-15Ta-6Zr alloy, and $62^{\circ}$ for the $\mathrm{HA}-\mathrm{ZrO} 2$ coated Ti-21Nb-15Ta-6Zr alloy.

The adhesion of the deposited material to the Ti alloys was mechanically tested from scratch tests using a disc pinion system, and measurements are drawn in Figure 5. When applying a speed of $0.50 \mathrm{~m} \mathrm{~s}^{-1}$, the friction coefficient reached an approximately constant value at the maximum force of 18 $\mathrm{N}$ in the case of the $\mathrm{HA}-\mathrm{ZrO}_{2}$ coated Ti-6Al-4V alloy (cf. Figure 5A), whereas there was a slight increase of the friction coefficient value when the normal force of $5 \mathrm{~N}$ was applied instead. Anyway, the frictional coefficient variation was relatively constant using either 5, 10 or $18 \mathrm{~N}$ applications to the coated Ti-6Al-4V alloy. In comparison, the friction coefficients exhibited higher values for the coated Ti-21Nb-15Ta-6Zr alloy. Furthermore, inspection of the SEM images of the coated surfaces determined 
after completing the friction tests show a more severe wear effect on the coating layers applied on Ti-6Al-4V than for Ti-21Nb-15Ta-6Zr ( see Figure 6).

\subsection{Electrochemical characterizations of the coatings}

The measured impedance spectra can be displayed in the form of a Nyquist complex plane plot, and/or as Bode diagrams. The Nyquist plot displays the impedance data by the complex variables and separated into its real, $Z_{\mathrm{re}}$, and imaginary, $Z_{\mathrm{im}}$, components, expressed in $\Omega \mathrm{cm}^{2}$. In the Bode diagram the frequency dependence of the absolute magnitudes of the impedance modulus, $|Z|$, and the phase angle, $\Phi$, are plotted instead. The frequency dependence of $\log |Z|$ and $\Phi$ indicate whether one or more time constants are present in the system.

The impedance data obtained for the $\mathrm{HA}-\mathrm{ZrO}_{2}$ coated and the uncoated $\mathrm{Ti}$ alloys at different exposures in the test electrolyte are displayed in the form of both Nyquist and Bode plots in Figures 7 and 8. In all cases, Nyquist diagrams show two depressed capacitive-like semicircles, one at high frequencies and another at intermediate and low frequency values. Also, the Bode-phase plots correspond to systems exhibiting two time constants as revealed by the presence of two maxima in these diagrams. The existence of two time constants in the Bode-phase spectra is an indication that their electrochemical responses can be separated into two distinct frequency regions. The two time constants are clearly observable within the frequency range in the case of the $\mathrm{HA}-\mathrm{ZrO}_{2}$ coated samples (see Figures 7D and 8D, respectively) even during the first day of immersion, while the bare metals do not always resolve the low-frequency maxima down to $1 \mathrm{mHz}$. This evidences that total impedance of the uncoated metals is actually greater than the values determined from the coated alloys.

An equivalent circuit (EC) was selected in order to describe the electrochemical behaviour of the coated and uncoated metal surfaces as derived from the EIS data. Given the depressed character of the semicircles seen in the Nyquist plots (i.e., Figures 7A,C and 8A,C), pseudo-capacitors elements $Q_{i}$ were used in the EC's. They were fitted as constant phase elements (CPE), and their impedance is given by:

$$
\mathrm{Z}_{\mathrm{CPE}}=\frac{1}{\mathrm{Q}(\mathrm{j} \omega)^{\mathrm{n}}}
$$


where $Q$ is the magnitude of the CPE, $\omega$ the angular frequency, $j$ the imaginary complex number $(-1)^{1 / 2}$, and the $n$ value indicates the nature of the element ( $n=0$ corresponds to a resistor, and $n=1$ means that the CPE behaves as a pure capacitor).

For the uncoated Ti alloys, equivalent circuits have been previously employed to describe the impedance behaviour of various Ti alloys exposed to physiological solutions [38-45]. Yet, most oxide layers formed on passivating metals, including most Ti alloys [46,47], usually present a duplex structure, with a thin compact inner layer and a somewhat more porous external layer that may be eventually penetrated by the electrolyte [48]. The latter accounts for the observation of a second time constant in the impedance spectra. Hence, data were modelled using ZsimpWin software by the equivalent circuit given in Figure 9A, which represents an unsealed inhomogeneous surface film [49]. This reflects the barrier characteristics of the oxide film towards electrolyte penetration that dominates the impedance response in the low frequency range (described by the time constant $R_{1} Q_{1}$ ), and to the charge transfer process in the surface of the alloys at higher frequencies (represented by $R_{2} Q_{2}$ ). The fitted parameters for the uncoated metals are listed in Table 1. The $R_{\text {sol }}$ of the test electrolyte, equal to $85 \pm 5 \Omega \mathrm{cm}^{-2}$, was observed for all the specimens, indifferent of the immersion time or the presence/absence of the coating, and was not inserted in the table. In summary, the data presented in Table 1 for the uncoated metals show an enhancement of the resistance of the films with the addition of $\mathrm{Nb}$, $\mathrm{Ta}$ and $\mathrm{Zr}$ content in the $\mathrm{Ti}$ alloy, as expected. Besides, the immersion time in Ringer's solution also results in an increase of both $R_{1}$ and $R_{2}$ values, evidencing the progressive development of a protective passive layer on the materials.

The electrochemical behaviour of the coated metals was fitted with the EC depicted in Figure 9B, representing an unsealed porous film [50]. The time constant in the high frequency region arises from the uncompensated ohmic resistance due to the electrolytic solution and the impedance characteristics resulting from the penetration of the electrolyte through a porous film. The $R_{1}$ and $Q_{1}$ parameters describe the processes occurring at the electrolyte/coating layer. The low frequency parts are attributed to the processes at the substrate/electrolyte interface. In this manner, $R_{1}$ represents the charge transfer resistance associated with the penetration of the electrolyte through the pores existing in the coated layer, and $Q_{1}$ corresponds to the pseudo-capacitance of the coating layer. Whilst, $R_{2}$ is the polarization resistance at the electrolyte/substrate interface in the pores, and $Q_{2}$ to the pseudocapacitance at the electrolyte/substrate layer interface which seems to be associated to the double layer formation. Such behaviour is typical of a metallic material coated with a porous nonreactive film. The 
resulting parameters are also listed in Table 1. From the fitted values of Table 1 some different features of the coated layer are observed. The $R_{1}$ values determined for each time of immersion are smaller than $R 2$ thus indicating that the coating layer is less protective in Ringer's solution. However, the increase of $R_{2}$ with the increase of the immersion time implies that Ti substrates become passive. The resistance values of the Ti-21Nb-15Ta-6Zr-HA-ZrO 2 surface eventually approach those of the bare metal, indicating a high corrosion resistance. Conversely, the corrosion resistance of the Ti-6Al-4V-HA-ZrO 2 surface seems to be mostly related to the high capacitance exhibited by the porous layer. The value of the polarization resistance indicates that both samples maintained for 7 days in Ringer's solution are still greatly resistant against corrosion. This behaviour may indicate the formation of a passive film on both Ti alloy surfaces, which hinders the onset of the corrosion process at the substrate.

In order to evaluate the heterogeneity of the sample surfaces, as well as their activity towards the electron transfer, SECM experiments were conducted in the feedback mode, with the addition of ferrocenemethanol as oxidizable redox mediator to the Ringer's solution. When the UME is placed in bulk solution and maintained at sufficient anodic potential, tip current attains a steady-state value given by:

$$
\mathrm{i}_{\mathrm{T}, \infty}=4 \pi n F D c r_{0}
$$

where $F$ is the faraday number, $D$ is the diffusion coefficient of the ferrocenemethanol, $c$ its concentration and $r_{0}$ the radius of the microdisk. Surface inactivity towards the electron transfer is reflected by the decrease on the tip current as probe is approached to the sample, since diffusion of the redox mediator becomes hindered by the UME itself (i.e. negative feedback). Conversely, conductive surfaces (or spots) which are thermodinamically and kinetically able to regenerate the redox mediator consumed at the tip, result in a current increase due to the increment of the redox active species in the vicinity of the UME (i.e. positive feedback). Both ideal situations can be modelled considering the tip geometry [51], and limited kinetic constants for the electron transfer at partially active surfaces provided mixed positive-negative feedback behaviour.

Figure 10 shows the PAC's measured with the UME moving towards the metal surfaces from the bulk solution. Uncoated metals immersed in Ringer's solution at $37{ }^{\circ} \mathrm{C}$ exhibit small current increments reflecting a partial regeneration of the redox mediator. Although mostly negative feedback 
was expected due to the inertness of the passive layers for the electron transfer [52,53], temperatures above room temperature will certainly produce an increase in the diffusion coefficients of the ferrocenemethanol/ferrocenium redox pair in the liquid and solid-porous interfaces, thus resulting in the observed mixed behaviour. Further approach of the tip resulted in the observation of a current peak, an indication of the eventual contact between the insulating glass of the microelectrode and the metallic surface. PAC's recorded at different locations of the surface exhibited similar behaviour though with variations in the magnitude of the maximum current increment.

The inactivity of the $\mathrm{HA}-\mathrm{ZrO}_{2}$ coatings towards the electron transfer resulted in pure negative feedback responses (cf. Figure 10B), indicating major inertness of the coated surfaces. This is apparently contradictory to the fitted EIS parameters discussed for Table 1, where resistance of the outer interfaces were estimated to be smaller for the coated surfaces. However, while the EIS technique interrogates all the current-exchange processes, including ionic motion between the interfaces, the SECM measurements are directed to explore the activity (thermodynamic and kinetic) of the conductive surfaces towards the transfer of an electron to the oxidized mediator. Besides, the higher capacitance values observed in most cases for the coated metals reflect dielectric thick and compact layers where the diffusion of the redox mediator is hindered, therefore impeding the transportation of the redox mediator to the electron transfer site, and its eventual electron exchange with the metal surface.

In order to evaluate the heterogeneity of the surface activity, 2-D scans were recorded and presented in Figure 11. It is noteworthy that all scans in the figure are displayed with the same colour scale for the sake of comparison, although the actual maximum and minimum values may exceed this scale. Again, mostly negative feedback behaviour is observed for the coated metals (cf. Figures 11A and 11C), while the uncoated surfaces exhibit normalized currents in excess of the diffusion-limited values registered in the bulk solution (i.e., normalized current values greater than 1). The Ti-6Al-4V surfaces, either coated or bare, appear to present a more heterogeneous behaviour than the Ti-21Nb-15Ta-6Zr specimens, with the former presenting some highly localized active and inactive spots for the coated and uncoated samples, respectively.

Figure 12 display typical potentiodynamic polarization curves recorded for the investigated materials after 7 days immersion in Ringer's solution at $37^{\circ} \mathrm{C}$. The corresponding corrosion potential ( $\left.E_{\text {corr }}\right)$ and corrosion current density $(j$ corr $)$ values were determined by Tafel analysis of both anodic and cathodic branches of the polarization plots. The average values of the corrosion potential and corrosion 
current density for each system determined from polarization curves are presented in Table 2. Since the polarization curves are typical of a direct transition from the immunity region to the passive region, the corrosion potential in these curves was defined by the intersection of the activation polarization anodic curve related to the formation of the passive film with the cathodic curve for the reduction reaction. The polarization curves showed a clear difference between the bare and the $\mathrm{HA}-\mathrm{ZrO} 2$ coated Ti alloys. The $E_{\text {corr }}$ of the $\mathrm{HA}-\mathrm{ZrO}_{2}$ coated $\mathrm{Ti}$ alloys was shifted by approximately $50 \mathrm{mV}$ toward more negative potentials, suggesting the occurrence of a porous film on the surface [54]. Furthermore, it was observed that the corrosion current density of $\mathrm{HA}-\mathrm{ZrO}_{2}$ coated metals was enhanced in comparison with the bare alloys. These data are in concordance with the EIS measurements, and indeed the coated samples are observed to be more susceptible to corrosion. The apparent contradiction with the SECM data reflects that the negative feedback observed with the coated metals arises mainly from the hindrance to diffusion imposed by the compact surface layers to the redox mediator, rather than originating from a greater resistance towards electron transfer at the metal-coating interface. The constant dissolution rate through the passive film that is usually observed in the passive region is because any increase in the potential is accompanied by progressive thickening of the layer [54]. Thus, for the $\mathrm{HA}-\mathrm{ZrO}_{2}$ coated alloy, the increase of the anodic current density with the increase of potential when the oxygen supply is limited seems to imply that the oxygen is essential for the growth of the passive film.

After completion of the dynamic polarization experiments, the coated surfaces were imaged with SEM in order to explore the eventual occurrence of morphological changes. Figure 13 presents the scanning electron micrographs of $\mathrm{HA}-\mathrm{ZrO}_{2}$ coated $\mathrm{Ti}$ alloys after anodic potentiodynamic polarization that were retrieved at +1.0 VSCE from the Ringer's solution. No obvious variations in the surface morphology of the $\mathrm{HA}-\mathrm{ZrO}_{2}$ coated $\mathrm{Ti}$ alloys as a result of the anodic polarization tests compared to its condition prior the testing were found.

\section{Conclusions}

In the present investigation, $\mathrm{HA}-\mathrm{ZrO}_{2}$ was deposited on $\mathrm{Ti}-21 \mathrm{Nb}-15 \mathrm{Ta}-6 \mathrm{Zr}$ and $\mathrm{Ti}-6 \mathrm{Al}-4 \mathrm{~V}$ alloys using PLD method. The $\mathrm{HA}-\mathrm{ZrO}_{2}$ coating modifies the electrochemical behaviour of the Ti alloys immersed in Ringer solutions. Corrosion resistance of $\mathrm{HA}-\mathrm{ZrO}_{2}$ coated and uncoated $\mathrm{Ti}$ alloys in Ringer's solution at $37^{\circ} \mathrm{C}$, was studied by EIS, SECM and potentiodynamic polarization technique. The 
results of EIS showed that the resistance of $\mathrm{HA}-\mathrm{ZrO}_{2}$ coated and uncoated Ti alloys increases slowly during 7 days immersion in Ringer's solution. The SECM data evidenced blocking surfaces where electron transfer with organometallic complexes seems to be hindered due to the compact $\mathrm{HA}-\mathrm{ZrO}_{2}$ coating. This suggests that the introduction of $\mathrm{HA}-\mathrm{ZrO}_{2}$ layers may not only provide beneficial interaction between implant and bone tissue, but also prevents from the interaction of the biomaterial with redox active molecules. The polarization curves of $\mathrm{HA}-\mathrm{ZrO}_{2}$ coated and uncoated Ti alloys shows typical active/passive transition behaviour. The corrosion rates of both coated Ti alloys determined from polarization curves are lower than $1 \mu \mathrm{A} \mathrm{cm}^{-2}$, and are typical of passive behaviour. It is believed that at this level corrosion will have negligible effect upon biochemical and cellular events at the bone-implant interface and could improve the osseointegration.

\section{Acknowledgments}

This work was supported by grants from the Romanian National Authority for Scientific Research, CNCS-UEFISCDI, project number PN-II-ID-PCE-2011-3-0218, and from the Ministerio de Economía y Competitividad (MINECO, Madrid, Spain) and the European Regional Development Fund (Brussels, Belgium) under Grant Number CTQ2012-36787.

\section{References}

[1] P. Kovacs, J.A. Davidson, Chemical and electrochemical aspects of the biocompatibility of titanium and its alloys, in: S.A. Brown, J.E. Lemons (Eds.), Medical Applications of Titanium and its Alloys: The Materials and Biological Issues, American Society for Testing and Materials, West Conshohocken, 1996, p. 163.

[2] M. Geetha, A.K. Singh, R. Asokamani, A.K. Gogia, Ti based biomaterials, the ultimate choice for orthopaedic implants - A review, Progress in Materials Science 54 (2009) 397-425.

[3] Y. Li, C. Yang, H. Zhao, S. Qu, X. Li, Y. Li, New developments of Ti-based alloys for biomedical applications, Materials 7 (2014) 1709-1800.

[4] M. Niinomi, Recent research and development in titanium alloys for biomedical applications and healthcare goods, Science and Technology of Advanced Materials 4 (2003) 445-454. 
[5] R.M. Souto, G.T. Burstein, A preliminary investigation into the microscopic depassivation of passive titanium implant materials in vitro, Journal of Materials Science: Materials in Medicine 7 (1996) 337-343.

[6] S. Rao, Y. Okazaki, T. Tateishi, T. Ushida, Y. Ito, Cytocompatibility of new Ti alloy without Al and V by evaluating the relative growth ratios of fibroblasts L929 and osteoblasts MC3T3-E1 cells, Materials Science and Engineering C 4 (1997) 311-314.

[7] Y. Okazaki, E. Gotoh, Comparison of metal release from various metallic biomaterials in vitro, Biomaterials 26 (2005) 11-21.

[8] N.J. Hallab, S. Anderson, M. Caicedo, A. Brasher, K. Mikecz, J.J. Jacobs, Effects of soluble metals on human periimplant cells, Journal of Biomedical Materials Research A 74 (2005) 124140.

[9] M. Niinomi, Mechanical biocompatibilities of titanium alloys for biomedical applications, Journal of the Mechanical Behavior of Biomedical Materials 1 (2008) 30-42.

[10] Y. Okazaki, S. Rao, T. Tateishi, Y. Ito, Cytocompatibility of various metal and development of new titanium alloys for medical implants, Materials Science and Engineering A 243 (1998) 250256.

[11] H. Matsuno, A. Yokoyama, F. Watari, M. Uo, T. Kawasaki, Biocompatibility and osteogenesis of refractory metal implants Ti, Hf, Nb, Ta, Rh, Biomaterials 22 (2001) 1253-1262.

[12] Y. Ikarashi, K. Toyoda, E. Kobayashi, H. Doi, T. Yoneyama, H. Hamanaka, T.Tsuchiya, Improved biocompatibility of titanium-zirconium (Ti-Zr) alloy: tissue reaction and sensitization of $\mathrm{Ti}-\mathrm{Zr}$ alloy compared with pure Ti and Zr in rat implantation study, Materials Transactions 46 (2005) 2260-2267.

[13] G. Bolat, J. Izquierdo, J.J. Santana, D. Mareci, R.M. Souto, Electrochemical characterization of ZrTi alloys for biomedical applications, Electrochimica Acta 88 (2013) 447-456.

[14] E.A. Trillo, C. Ortiz, P. Dickerson, R. Villa, S.W. Stafford, L.E. Murr, Evaluation of mechanical and corrosion biocompatibility of TiTa alloys, Journal of Materials Science: Materials in Medicine 12 (2001) 283-292.

[15] L.M. Elias, S.G. Schneider, S. Schneider, H.M. Silva, F. Malvisi, Microstructural and mechanical characterization of biomedical Ti-Nb-Zr(-Ta) alloys, Materials Science and Engineering A 432 (2006) 108-112. 
[16] S.L. Assis, S. Wolynec, I. Costa, The electrochemical behaviour of Ti-13Nb-13Zr alloy in various solutions, Materials and Corrosion 59 (2008) 739-743.

[17] S. Johnson, M. Haluska, R.J. Narayan, R.L. Snyder, In situ annealing of hydroxyapatite thin films, Materials Science and Engineering C 26 (2006) 1312-1316.

[18] C.-L. Liao, F.-H. Lin, K.-S. Chen, J.-S. Sun, Thermal decomposition and reconstitution of hydroxyapatite in air atmosphere, Biomaterials 20 (1999) 1807-1813.

[19] S .Raynaud, E .Champion, D. Bernache-Assollant, P .Thomas, Calcium phosphate apatites with variable $\mathrm{Ca} / \mathrm{P}$ atomic ratio I. Synthesis, characterisation and thermal stability of powders, Biomaterials 23 (2002) 1065-1072.

[20] R. Kelly, A. Miotello, Mechanisms of pulsed laser sputtering, in: D.B. Chrisey, G.K. Hubler (Eds.), Pulsed Laser Deposition of Thin Films, Wiley, New York, 1994, pp. 55-89.

[21] W.B. Ian, Thin film growth by pulsed laser deposition, Ceramics International 22 (1996) 429-434.

[22] S.M. Kaczmarek, Pulsed laser deposition - today and tomorrow, in: Laser Technology V: Applications in Materials Science and Engineering, SPIE Proceedings 3187 (1997) 129-134.

[23] Q. Bao, C. Chen, D. Wang, Q. Ji, T. Lei, Pulsed laser deposition and its current research status in preparing hydroxyapatite thin film, Applied Surface Science 252 (2005) 1538-1544.

[24] L.C. Nistor, C. Ghica, V.S. Teodorescu, S.V. Nistor, M. Dinescu, D. Matei, N. Frangis, N. Vouroutzis, C. Liutas, Deposition of hydroxyapatite thin films by Nd:YAG laser ablation: A microstructural study, Materials Research Bulletin 39 (2004) 2089-2101.

[25] D. Mareci, N. Cimpoesu, M.I. Popa, Electrochemical and SEM characterization of NiTi alloy coated with chitosan by PLD technique, Materials and Corrosion 63 (2012) 985-991.

[26] Y. Huang, X. Zhang, R. Zhao, H. Mao, Y. Yan, X. Pang, Antibacterial efficacy, corrosion resistance, and cytotoxicity studies of copper-substituted carbonated hydroxyapatite coating on titanium substrate, Journal of Materials Science 50 (2015) 1688-1700.

[27] Y. Huang, X. Zhang, H. Mao, T. Lin, R. Zhao, Y. Yan, X. Pang, Osteoblastic cell responses and antibacterial efficacy of $\mathrm{Cu} / \mathrm{Zn}$ co-substituted hydroxyapatite coatings on pure titanium using electrodeposition method, RSC Advances 5 (2015) 17076-17086.

[28] Y. Suda, H. Kawasaki, T. Ohshima, S. Nakashima, S. Kawazoe, T. Toma, Hydroxyapatite coatings on titanium dioxide thin films prepared by pulsed laser deposition method, Thin Solid Films 506507 (2006) 115-119. 
[29] B. Feddes, A.M. Vredenberg, M. Wehner, J.C. Wolke, J.A. Jansen, Laser-induced crystallization of calcium phosphate coatings on polyethylene (PE), Biomaterials 26 (2005) 1645-1651.

[30] Y. Hu, X. Miao, Comparison of hydroxyapatite ceramics and hydroxyapatite/borosilicate glass composites prepared by slip casting, Ceramics International 30 (2004) 1787-1791.

[31] D.G. Wang, C.Z. Chen, Q.S. Ma, Q.P. Jin, H.C. Li, A study on in vitro and in vivo bioactivity of HA/45S5 composite films by pulsed laser deposition, Applied Surface Science 270 (2013) 667674.

[32] R. Chelariu, D. Mareci, G. Bolat, C.A. Peptu, D. Cailean, Electrochemical characterization of surface modification for Ti6Al7Nb implants with hydroxyapatite-zirconia nanoparticles synthesis by ultrasound irradiations, Materials and Corrosion 66 (2015) 573-578.

[33] D. Mareci, R. Chelariu, G. Ciurescu, D. Sutiman, T. Gloriant, Electrochemical aspects of Ti-Ta alloys in HBSS, Materials and Corrosion 61 (2010) 768-774.

[34] G. Ciurescu, J. Izquierdo, J.J. Santana, D. Mareci, D. Sutiman, S. González, R.M. Souto, Characterization of the localized surface chemical activity of Ti-Mo and Ti-Ta alloys for biomedical applications using scanning electrochemical microscopy, International Journal of Electrochemical Science 7 (2012) 7404-7424.

[35] R. Chelariu, G. Bolat, J. Izquierdo, D. Mareci, D.M. Gordin, T. Gloriant, R.M. Souto, Metastable beta Ti-Nb-Mo alloys with improved corrosion resistance in saline solution, Electrochimica Acta 137 (2014) 280-289.

[36] J. Izquierdo, M.B. González-Marrero, M. Bozorg, B.M. Fernández-Pérez, H.C. Vasconcelos, J.J. Santana, R.M. Souto, Multiscale electrochemical analysis of the corrosion of titanium and nitinol for implant applications, Electrochimica Acta 203 (2016) 366-378

[37] F.-R. F. Fan, Ch. Demaille, Preparation of tips for scanning electrochemical microscopy, in: A.J. Bard, M.V. Mirkin (Eds.), Scanning Electrochemical Microscopy, $2^{\text {nd }}$ edition, CRC Press, Boca Raton, 2012, Ch. 3.

[38] B.L. Wang, Y.F. Zheng, L.C. Zhao, Effects of Hf content and immersion time on electrochemical behavior of biomedical Ti-22Nb-xHf alloys in $0.9 \% \mathrm{NaCl}$ solution, Materials and Corrosion 60 (2009) 330-335.

[39] X. Cheng, S.G. Roscoe, Corrosion behavior of titanium in the presence of calcium phosphate and serum proteins, Biomaterials 26 (2005) 7350-7356. 
[40] S. Tamilselvi, N. Rajendran, Electrochemical studies on the stability and corrosion resistance of Ti-5Al-2Nb-1Ta alloy for biomedical applications, Trends in Biomaterials \& Artificial Organs 20 (2006) 49-52.

[41] S. Tamilselvi, R. Murugaraj, N. Rajendran, Electrochemical impedance spectroscopic studies of titanium and its alloys in saline medium, Materials and Corrosion 58 (2007) 113-120.

[42] S. Tamilselvi, N. Rajendran, In vitro corrosion behaviour of Ti-5Al-2Nb-1Ta alloy in Hanks solution, Materials and Corrosion 58 (2007) 285-289.

[43] S.E. Kim, J.H. Son, Y.T. Hyun, H.W. Jeong, Y.T. Lee, J.S. Song, J.H. Lee, Electrochemical corrosion of novel beta titanium alloys, Metals and Materials International 13 (2007) 151-154.

[44] M.E.P. Souza, L. Lima, C.R.P. Lima, C.A.C. Zavaglia, C.M.A. Freire, Effects of pH on the electrochemical behavior of titanium alloys for implant applications, Journal of Materials Science: Materials in Medicine 20 (2009) 549-552.

[45] C.W. Chan, H,C, Man, T.M. Yue, Effect of post-weld heat-treatment on the oxide film and corrosion behaviour of laser-welded shape memory NiTi wires, Corrosion Science 56 (2012) 158167.

[46] J. Pan, D. Thierry, C. Leygraf, Electrochemical impedance spectroscopy study of the passive oxide film on titanium for implant application, Electrochimica Acta 41 (1996) 1143-1153.

[47] V.A. Alves, R.Q. Reis, I.C.B. Santos, D.G. Souza, T. de F. Gonçalves, M.A. Pereira-da-Silva, A. Rossi, L.A. da Silva, In situ impedance spectroscopy study of the electrochemical corrosion of $\mathrm{Ti}$ and Ti-6Al-4V in simulated body fluid at $25^{\circ} \mathrm{C}$ and $37{ }^{\circ} \mathrm{C}$, Corrosion Science 51 (2009) 24732482.

[48] D. Wallinder, J. Pan, C. Leygraf, A. Delblanc-Bauer, EIS and XPS study of surface modification of 316LVM stainless steel after passivation, Corrosion Science 41 (1999) 275-289.

[49] F. Mansfeld, Analysis and interpretation of EIS data for metals and alloys, Technical Report 26, Solartron-Schlumberger, Farnborough, 1993, Ch. 4.

[50] R.M. Souto, M.M. Laz, R.L. Reis, Degradation characteristics of hydroxyapatite coatings on orthopedic TiAlV in simulated physiological media investigated by electrochemical impedance spectroscopy, Biomaterials 24 (2003) 4213-4221. 
[51] R. Cornut, C. Lefrou, New analytical approximation of feedback approach curves with a microdisk SECM tip and irreversible kinetic reaction at the substrate, Journal of Electroanalytical Chemistry 621 (2008) 178-184.

[52] S.E. Pust, D. Scharnweber, S. Baunack, G. Wittstock, Electron transfer kinetics at oxide films on metallic biomaterials. scanning electrochemical microscopy studies of Ti6Al4V, Journal of The Electrochemical Society, 154 (2007) C508-C514.

[53] F. Billi, E. Onofre, E. Ebramzadeh, T. Palacios, M.L. Escudero, M.C. Garcia-Alonso, Characterization of modified Ti6Al4V alloy after fretting-corrosion tests using near-field microscopy, Surface and Coatings Technology 212 (2012) 134-144.

[54] I.C. Lavos-Valereto, I. Costa, S. Wolynec, The electrochemical behaviour of Ti-6Al-7Nb alloy with and without plasma-sprayed hydroxyapatite coating in Hank's solution, Journal of Biomedical Materials Research B: Applied Biomaterials 63 (2002) 664-670. 
Table 1. Impedance parameters of $\mathrm{HA}-\mathrm{ZrO}_{2}$ coated and bare Ti-21Nb-15Ta-6Zr and Ti-6Al-4V alloys immersed in naturally-aerated Ringer's solution at $37^{\circ} \mathrm{C}$ after different immersion periods.

\begin{tabular}{|c|c|c|c|c|c|c|c|}
\hline Alloy & $\begin{array}{l}\text { Immersion } \\
\text { time }\end{array}$ & $\begin{array}{c}Q_{1} / \\
\mathrm{mS} \mathrm{cm}^{-2} \mathrm{~s}^{n}\end{array}$ & $n_{1}$ & $\begin{array}{c}R_{1} / \\
\mathrm{k} \Omega \mathrm{cm}^{2}\end{array}$ & 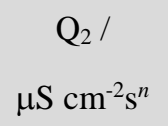 & $n_{2}$ & $\begin{array}{c}R_{2} / \\
\mathrm{M} \Omega \mathrm{cm}^{2}\end{array}$ \\
\hline \multirow{3}{*}{$\begin{array}{c}\text { Uncoated } \\
\text { Ti-21Nb-15Ta-6Zr }\end{array}$} & 1 hour & 1 & 0.84 & 42 & 9 & 0.82 & 0.25 \\
\hline & 1 day & 1 & 0.85 & 47 & 7 & 0.83 & 0.35 \\
\hline & 7 days & 1 & 0.85 & 49 & 7 & 0.83 & 0.39 \\
\hline \multirow{3}{*}{$\begin{array}{l}\text { Uncoated } \\
\text { Ti-6Al-4V }\end{array}$} & 1 hour & 2 & 0.82 & 15 & 9 & 0.82 & 0.11 \\
\hline & 1 day & 2 & 0.83 & 18 & 9 & 0.82 & 0.13 \\
\hline & 7 days & 1 & 0.83 & 21 & 8 & 0.82 & 0.16 \\
\hline \multirow{3}{*}{$\begin{array}{l}\text { HA-ZrO }{ }_{2} \text { coated } \\
\text { Ti-21Nb-15Ta-6Zr }\end{array}$} & 1 hour & 2 & 0.83 & 21 & 9 & 0.81 & 0.18 \\
\hline & 1 day & 2 & 0.83 & 23 & 9 & 0.82 & 0.24 \\
\hline & 7 days & 1 & 0.84 & 29 & 8 & 0.82 & 0.29 \\
\hline \multirow{3}{*}{$\begin{array}{c}\mathrm{HA}-\mathrm{ZrO}_{2} \text { coated } \\
\text { Ti-6Al-4V }\end{array}$} & 1 hour & 44 & 0.84 & 1 & 21 & 0.81 & 0.03 \\
\hline & 1 day & 43 & 0.84 & 1 & 17 & 0.82 & 0.06 \\
\hline & 7 days & 41 & 0.85 & 3 & 9 & 0.82 & 0.11 \\
\hline
\end{tabular}


Table 2. Corrosion parameters (and standard deviation values) determined from the potentiodynamic polarization curves for $\mathrm{HA}-\mathrm{ZrO}_{2}$ coated and bare Ti-21Nb-15Ta-6Zr and Ti-6Al-4V alloys immersed in naturally-aerated Ringer's solution at $37^{\circ} \mathrm{C}$ for 7 days.

\begin{tabular}{ccccc}
\hline Alloy & $E_{\text {corr }} / \mathrm{mV}_{\mathrm{SCE}}$ & $j_{\text {corr }} / \mu \mathrm{A} \mathrm{cm}^{-2}$ & $-\beta_{\mathrm{c}} / \mathrm{mV} \mathrm{dec}^{-1}$ & $\beta_{\mathrm{a}} / \mathrm{mV} \mathrm{dec}^{-1}$ \\
\hline $\begin{array}{c}\text { HA-ZrO} \\
\text { Ti-21Nb-15Ta-6Zr }\end{array}$ & $-572(15)$ & $0.94(0.09)$ & $176(12.3)$ & $147(9.3)$ \\
$\begin{array}{c}\mathrm{HA}-\mathrm{ZrO}{ }_{2} \text { Coated } \\
\text { Ti-6Al-4V }\end{array}$ & $-596(17)$ & $1.21(0.13)$ & $172(11.9)$ & $141(10.1)$ \\
\hline $\begin{array}{c}\text { Uncoated } \\
\text { Ti-21Nb-15Ta-6Zr }\end{array}$ & $-512(16)$ & $0.69(0.05)$ & $183(12.5)$ & $152(11.3)$ \\
$\begin{array}{c}\text { Uncoated Ti-6Al-4V } \\
\text { Und }\end{array}$ & $-551(20)$ & $0.84(0.07)$ & $188(13.2)$ & $149(10.7)$ \\
\hline
\end{tabular}
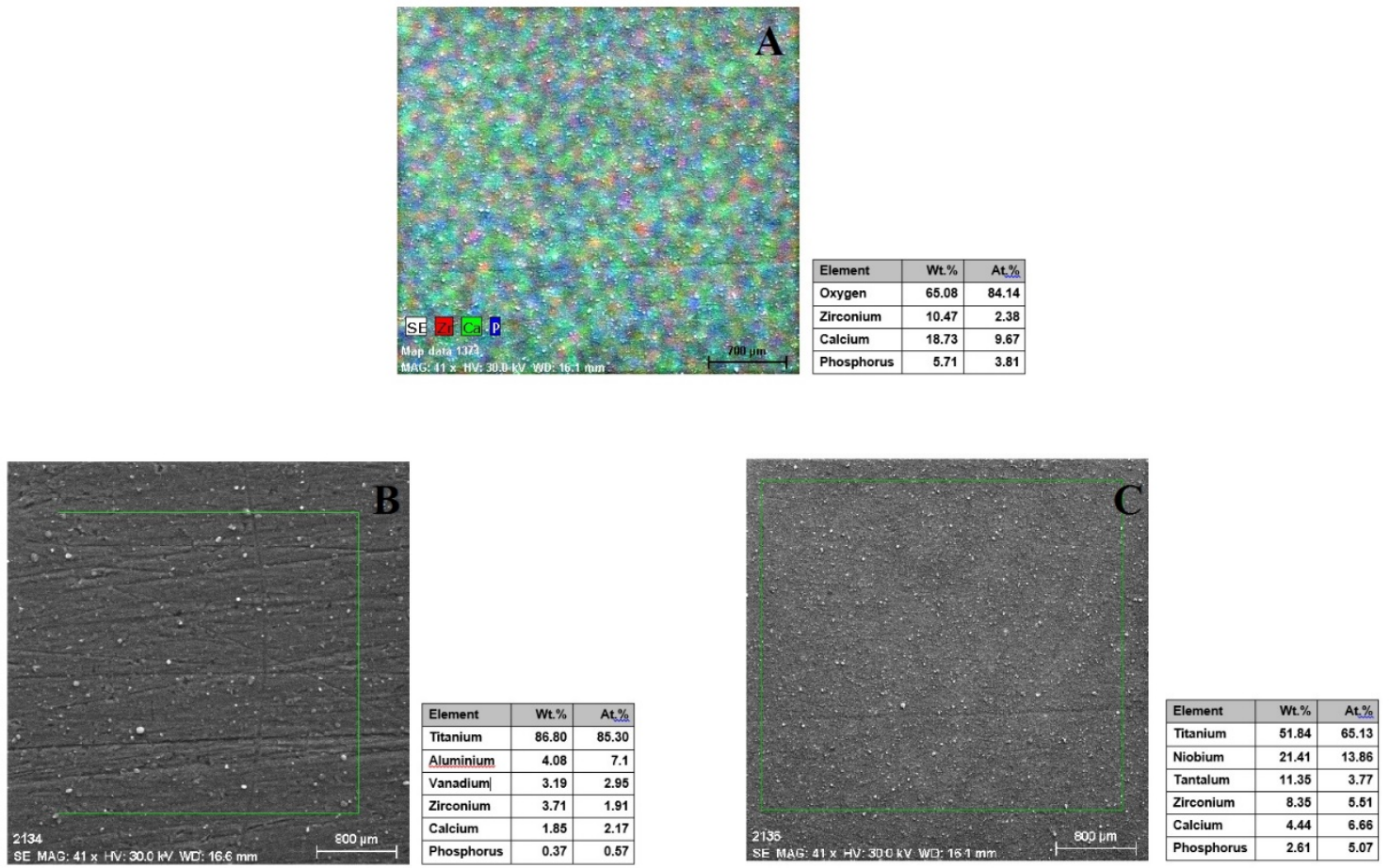

Figure 1. Surface characterization of the $\mathrm{HA}-\mathrm{ZrO}_{2}$ coating. Representative EDX analysis of: (A) the $\mathrm{HA}-\mathrm{ZrO} 2$ compacted target, (B) HA-ZrO 2 coated Ti-6Al-4V alloy, and (C) HA-ZrO 2 coated Ti-21Nb15Ta-6Zr alloy. 

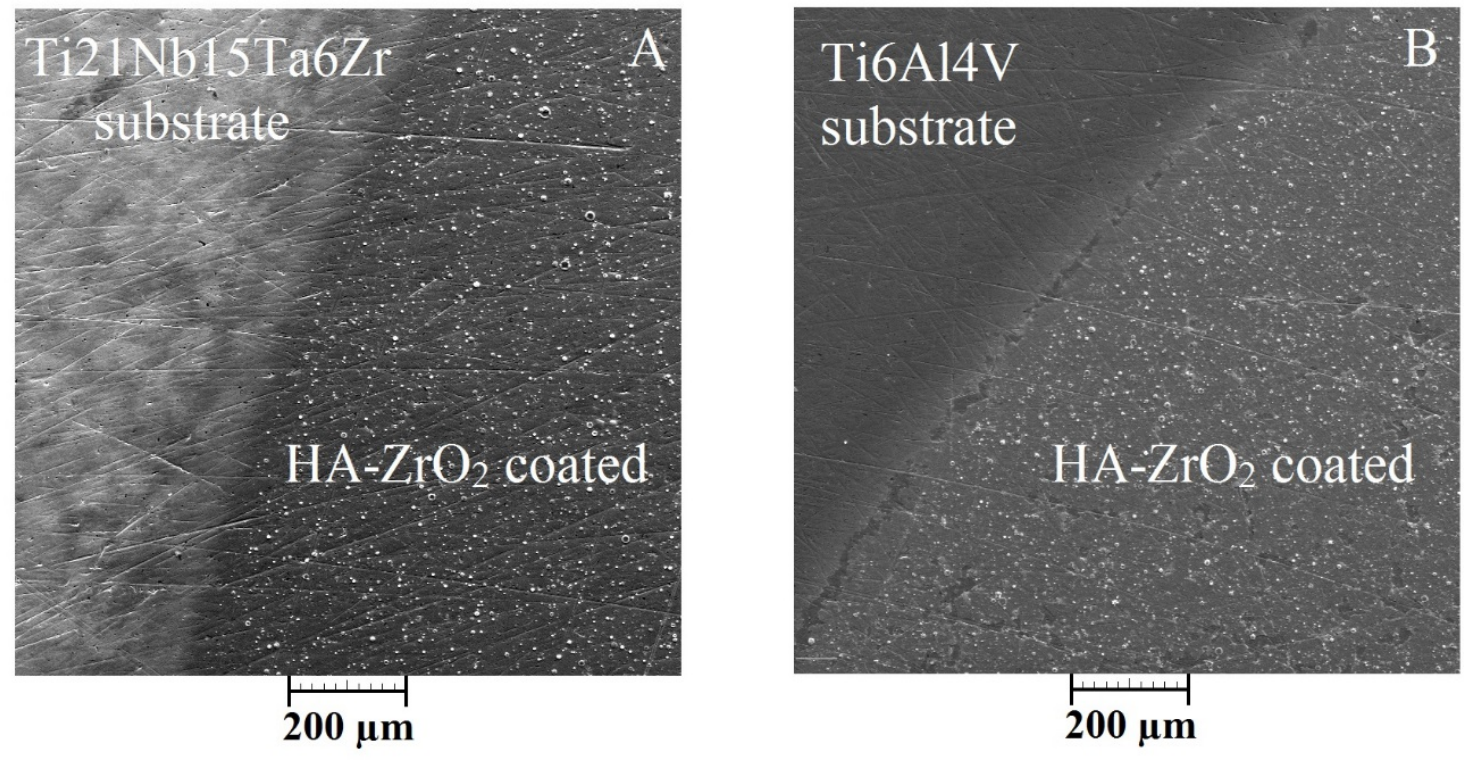

Figure 2. SEM images of the boundary between the $\mathrm{HA}-\mathrm{ZrO}_{2}$ coating and (B) Ti-6Al-4V, (C) Ti-21Nb15Ta-6Zr bare alloys.

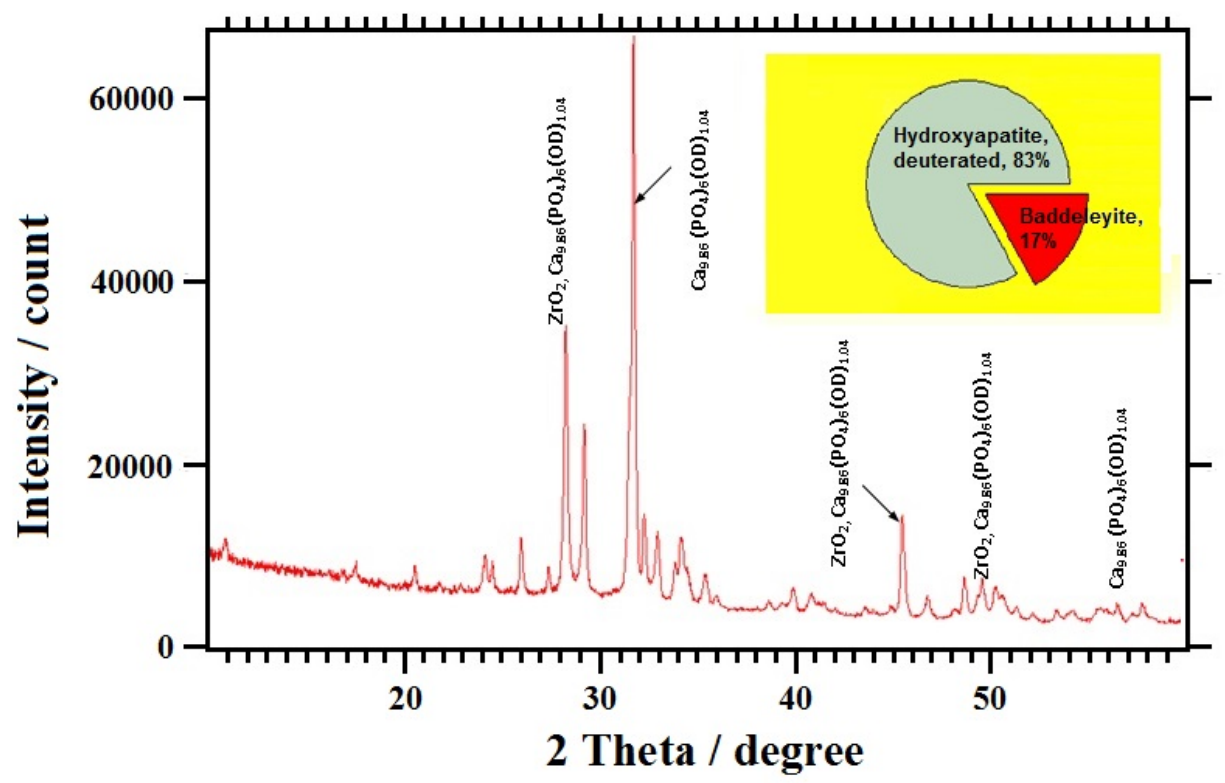

Figure 3. X-ray diffractometry pattern measured for hydroxyapatite-zirconia coated Ti-21Nb-15Ta-6Zr alloy. 

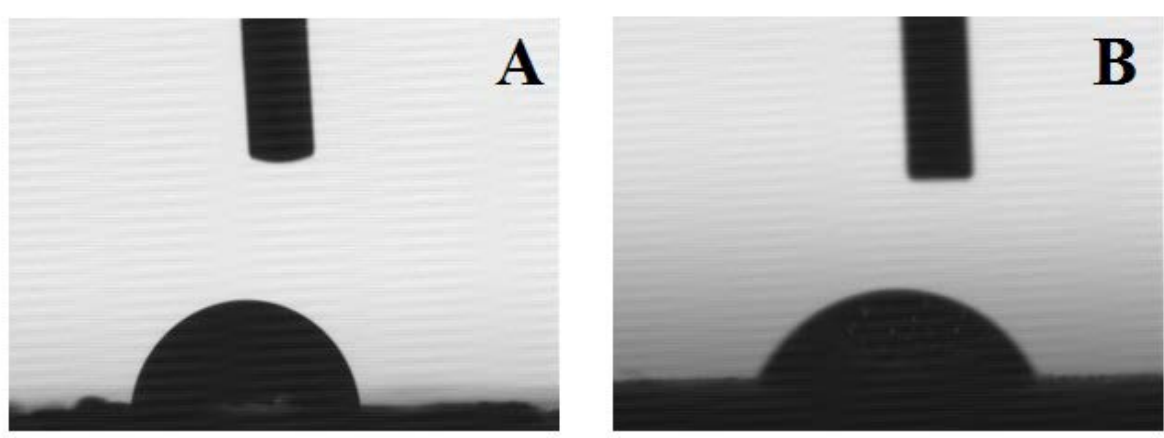

Figure 4. Shape of the liquid drop applied on (A) uncoated, and (B) hydroxyapatite-zirconia coated Ti-21Nb-15Ta-6Zr alloy.
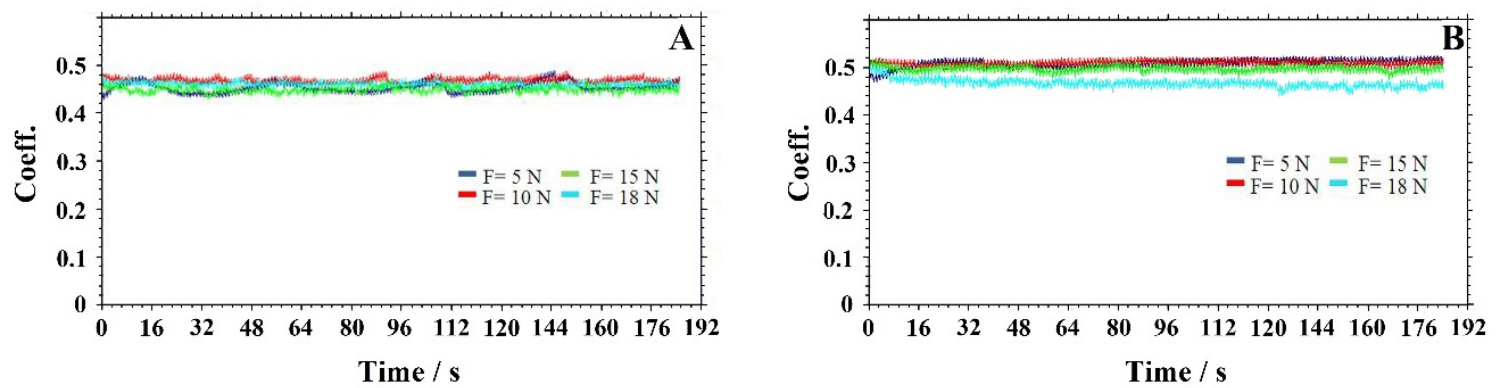

Figure 5. Friction behaviour of the $\mathrm{HA}-\mathrm{ZrO}_{2}$ coated $\mathrm{Ti}$ alloys during scratc tests using a disc pinion system: (A) Ti-6Al-4V, and (B) Ti-21Nb-15Ta-6Zr alloys.
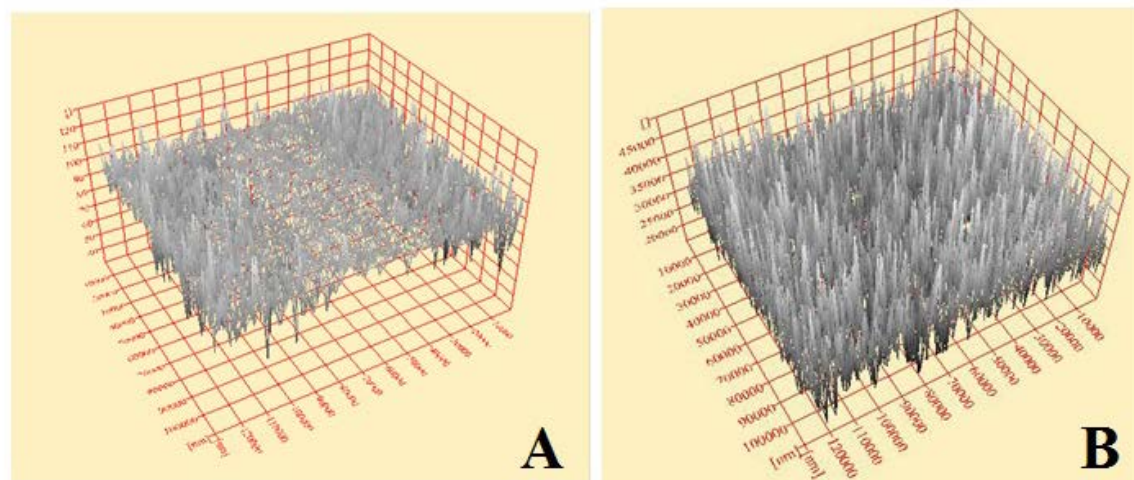

Figure 6. 3-D SEM micrographs of hydroxyapatite-zircoania coated Ti alloys after completing the scratch tests of Figure 5. (A) Ti-6Al-4V, and (B) Ti-21Nb-15Ta-6Zr alloys. 

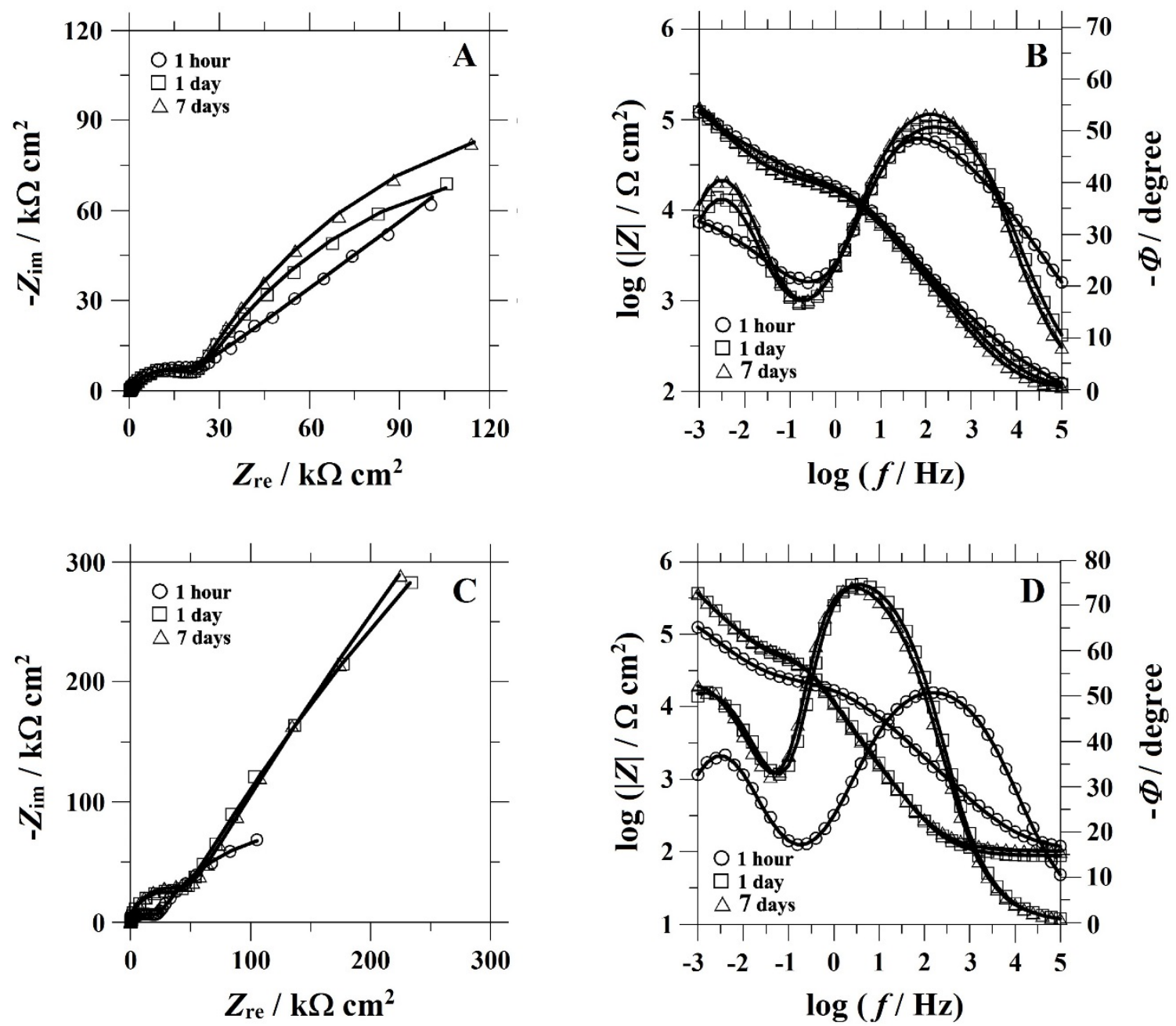

Figure 7. Nyquist $(\mathrm{A}, \mathrm{C})$ and Bode $(\mathrm{B}, \mathrm{D})$ impedance diagrams for $(\mathrm{A}, \mathrm{B}) \mathrm{HA}-\mathrm{ZrO}_{2}$ coated and $(\mathrm{C}, \mathrm{D})$ bare Ti-21Nb-15Ta-6Zr alloy at the corresponding OCP during exposure to Ringer's solution for various immersion times as indicated. 



Figure 8. Nyquist $(A, C)$ and Bode $(B, D)$ impedance diagrams for $(A, B) H A-Z_{2} \mathrm{O}_{2}$ coated and $(C, D)$ bare Ti-6Al-4V alloy at the corresponding OCP during exposure to Ringer's solution for various immersion times as indicated.


Figure 9. Equivalent circuits (EC) used for fitting the measured impedance spectra: (A) case of a duplex oxide film on the metal, and (B) case of an unsealed $\mathrm{HA}-\mathrm{ZrO}_{2}$ porous layer. 

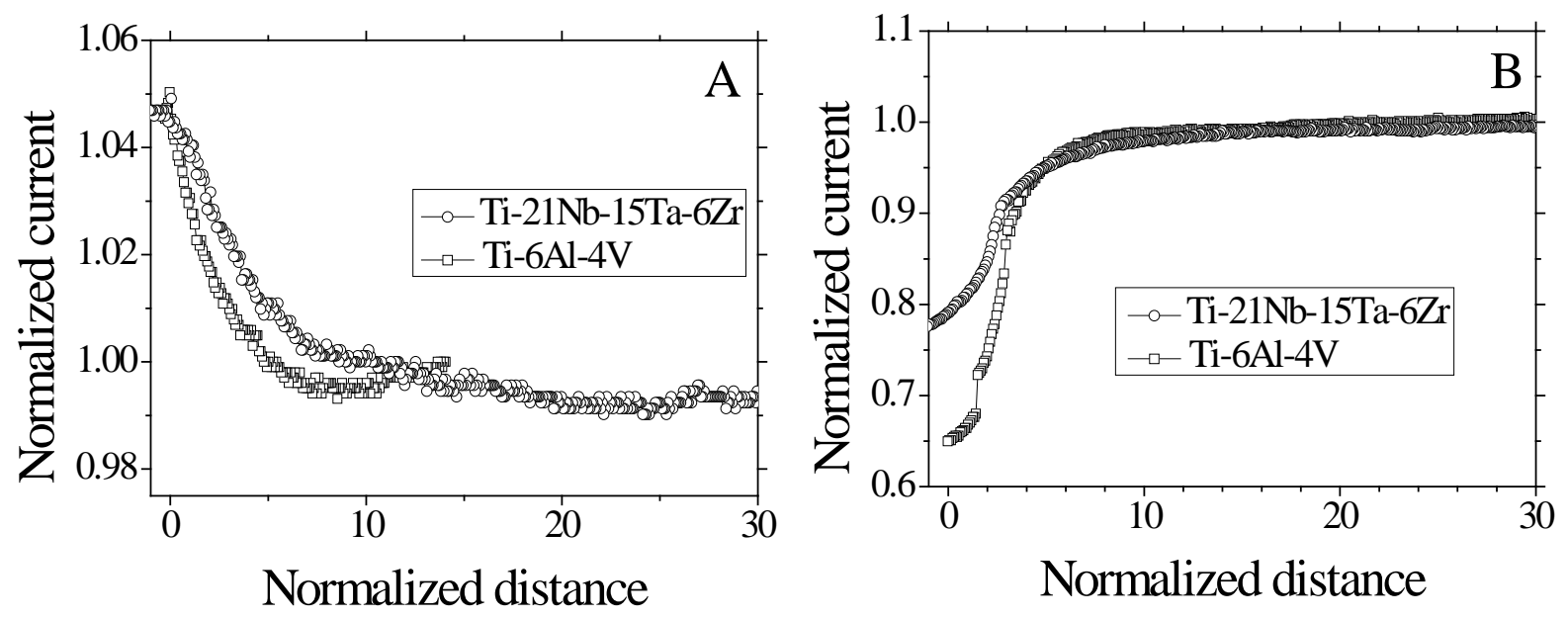

Figure 10. Probe approach curves (PAC) recorded with the SECM tip moving towards the (a) bare and (b) coated Ti alloys in ferrocenemethanol-containing Ringer's solution at $37^{\circ} \mathrm{C}$.
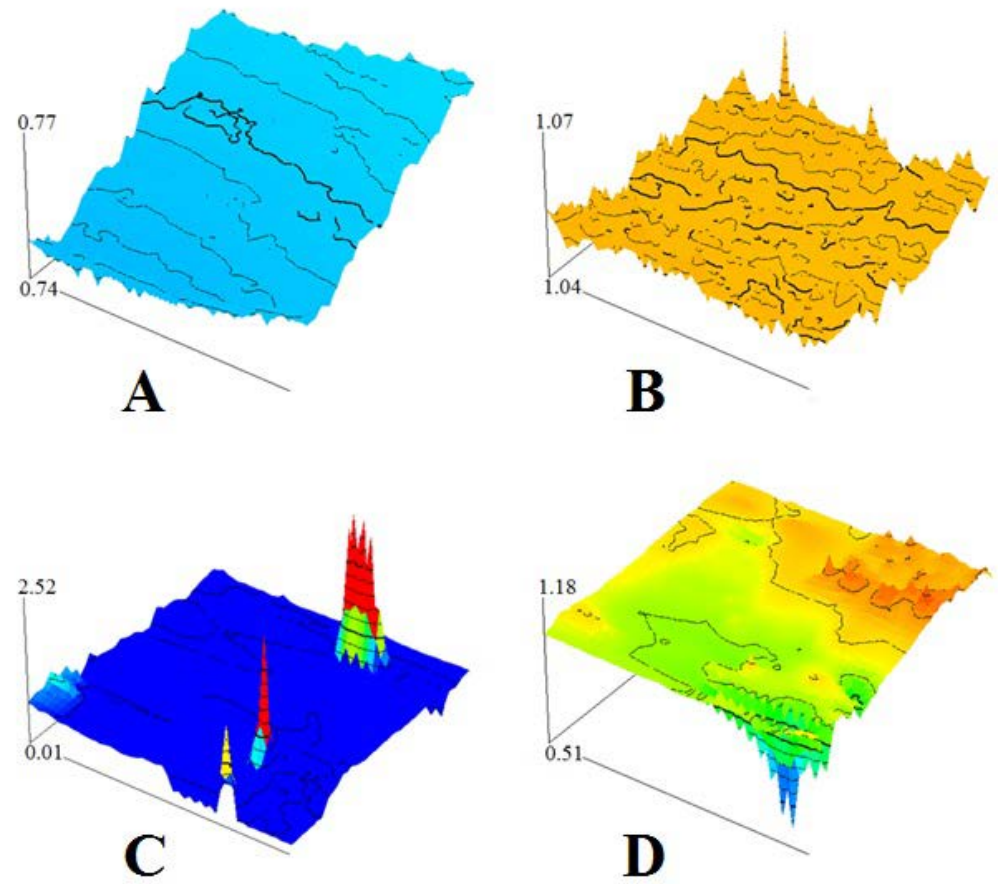

Normalized tip current

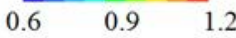

Figure 11. 2-D scans recorded with the SECM tip moving over: (A) $\mathrm{HA}^{-} \mathrm{ZrO}_{2}$ coated Ti-21Nb-15Ta-6Zr, (B) bare Ti-21Nb-15Ta-6Zr, (C) HA-ZrO2 coated Ti-6Al-4V, and (d) bare Ti-6Al-4V alloys in ferrocenemethanol-containing Ringer's solution at $37{ }^{\circ} \mathrm{C}$. The scans represent a randomly chosen area of $250 \times 250 \mu^{2}$. 

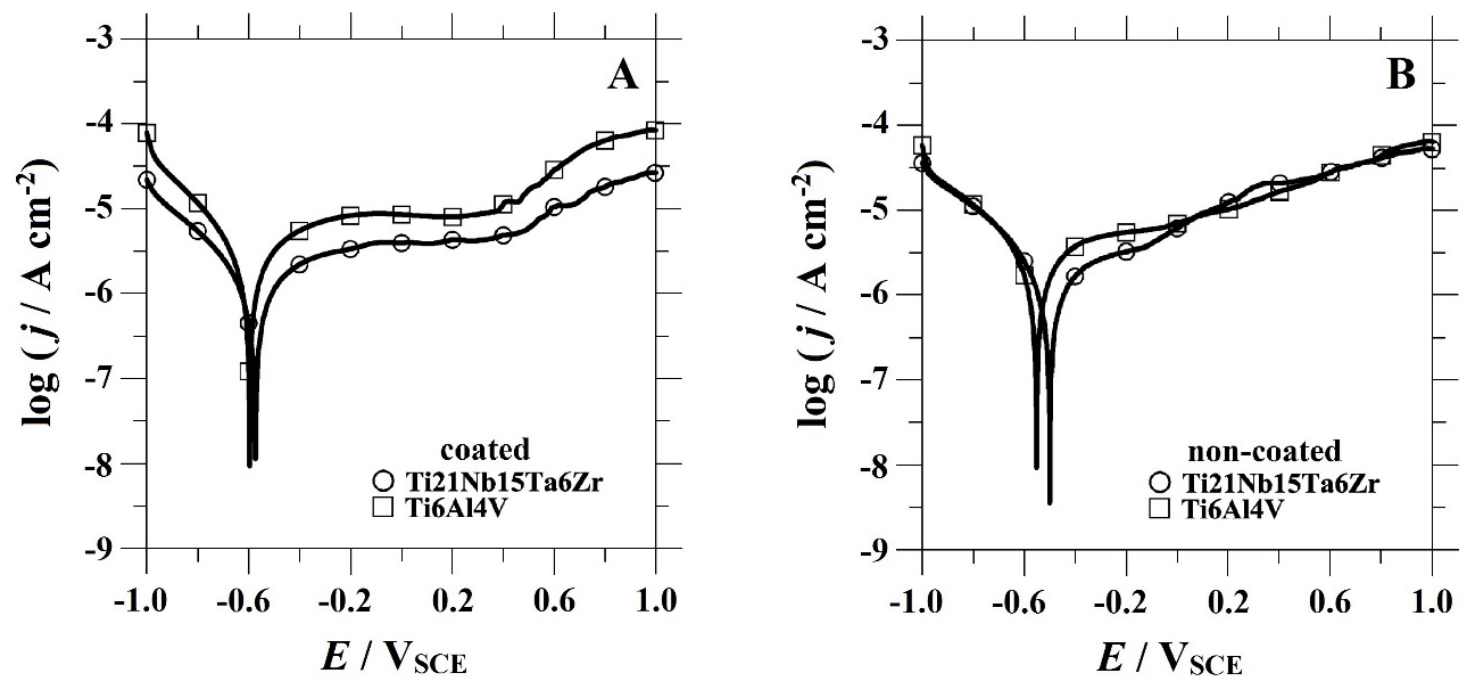

Figure 12. Potentiodynamic polarization curves of: (A) $\mathrm{HA}-\mathrm{ZrO}_{2}$ coated and (B) bare Ti alloy samples after 7 days of immersion in Ringer's solution at $37^{\circ} \mathrm{C}$.
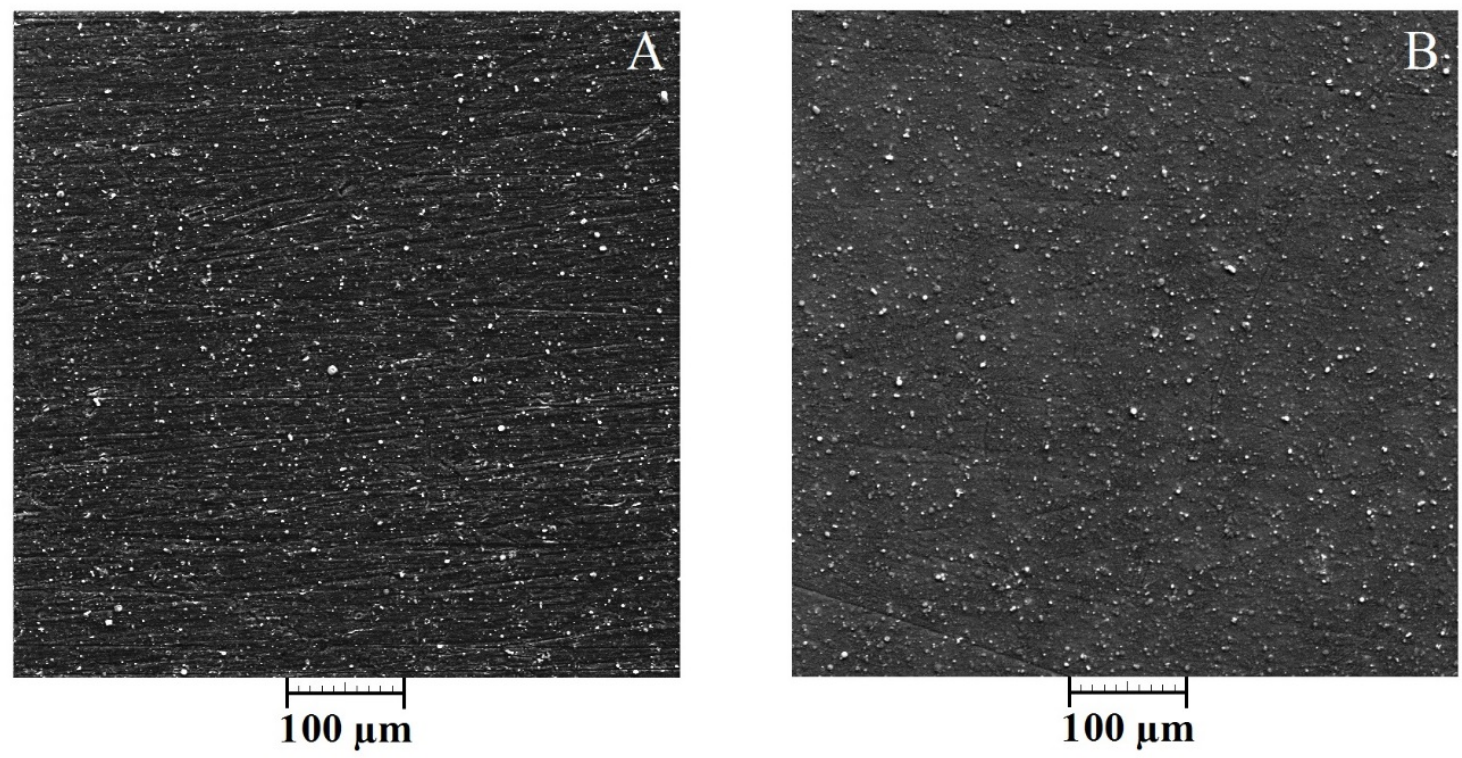

Figure 13. SEM micrographs of retrieved $\mathrm{HA}-\mathrm{ZrO}_{2}$ coated $\mathrm{Ti}$ alloy samples retrieved at $+1.0 \mathrm{VSCE}$ after polarization tests in Ringer's solution at $37{ }^{\circ} \mathrm{C}$ : (A) Ti-21Nb-15Ta-6Zr, and (B) Ti-6Al-4V alloys. 